\title{
Construção de objetos de conhecimento para aulas de língua portuguesa na abordagem do letramento científico
}

\section{Construction of knowledge objects for Portuguese language classes in the scientific literacy approach}

\author{
Wagner Rodrigues Silva* \\ Universidade Federal do Tocantins - UFT \\ Palmas - Tocantins / Brasil \\ Elton Viera Guimarães** \\ Universidade Federal do Tocantins - UFT \\ Araguaína - Tocantins / Brasil \\ Ivanildo Alves Medeiros ${ }^{* * *}$ \\ Universidade Federal do Tocantins - UFT \\ Araguaína - Tocantins / Brasil
}

\begin{abstract}
RESUMO: Investigamos uma experiência de formação de professores de língua portuguesa, orientada pela abordagem do letramento científico, num mestrado profissional ofertado pelo governo brasileiro como programa de instrução de professores vinculados a escolas públicas. Os documentos investigados foram textos produzidos pelos próprios professores em formação na experiência focalizada, além de um documento oficial proposto para determinar, principalmente, disciplinas, conteúdos e habilidades a serem obrigatoriamente trabalhados nas escolas básicas brasileiras. No final deste artigo, apresentamos uma proposta de atividade pedagógica como resultado do alinhamento de conhecimentos produzidos na experiência investigada de formação de professores.
\end{abstract}

PALAVRAS-CHAVE: gramática; leitura; letramento científico; interdisciplinaridade; Linguística Aplicada.

\footnotetext{
* wagnerodriguesilva@gmail.com. Bolsista de Produtividade do CNPq.

** elton@uft.edu.br. Mestrado Profissional em Letras (ProfLetras).

*** ivanildo33@hotmail.com. Mestrado Profissional em Letras (ProfLetras)
} 


\begin{abstract}
We investigate a training experience of Portuguese language teachers, guided by the scientific literacy approach, in a professional master's degree offered by the Brazilian government as a teachers instruction program linked up to public schools. The investigated documents were texts produced by the own teachers in training during the program in question, in addition to an official document that was proposed to determine, mainly, subjects, contents and skills to be compulsorily worked on Brazilian basic schools. At the end of this article, we present a proposal of pedagogical activity as result of alignment of knowledges produced in the investigated experience of teacher training.
\end{abstract}

KEYWORDS: grammar; reading; scientific literacy; interdisciplinarity; Applied Linguistics.

\title{
1 Introdução
}

A partir de algumas demandas apresentadas por professoras atuantes no ensino básico brasileiro, apresentamos uma proposta de atividade pedagógica, articulando os componentes curriculares de língua portuguesa e ciências. ${ }^{1}$ Para tanto, levamos em consideração algumas recomendações da terceira edição preliminar da Base Nacional Comum Curricular - BNCC (BRASIL, 2017), que, apesar de desencadear debates acalorados em torno dos objetos de conhecimento selecionados, reúne produtivas abordagens pedagógicas focalizadas em pesquisas científicas, a exemplo do ensino interdisciplinar e do trabalho escolar na perspectiva dos letramentos.

Esta pesquisa é de natureza qualitativa com enfoque interpretativo de manuscritos produzidos por professoras de língua portuguesa (LP), matriculadas em uma das turmas do Mestrado Profissional em Letras (ProfLetras) ofertado na Universidade Federal do Tocantins. ${ }^{2}$ Tais profissionais residem e atuam nos estados do Maranhão (MA) e do Tocantins (TO). Os documentos investigados correspondem a textos configurados entre os gêneros relato de experiência e ensaio acadêmico, produzidos em resposta às seguintes questões, apresentadas pelo formador

\footnotetext{
${ }^{1}$ Este artigo apresenta resultados de investigações produzidas no grupo de pesquisa Práticas de Linguagens - PLES (UFT/CNPq).

2 Optamos por utilizar o gênero feminino para fazer referência à turma do Mestrado Profissional em Letras (ProfLetras/UFT), uma vez que era composta por treze alunas e dois alunos, todas professoras de língua portuguesa em escolas públicas. De alguma forma, essa proporção ilustra o contexto profissional nas escolas básicas brasileiras, formado principalmente por mulheres.
} 
responsável pela disciplina Alfabetização e Letramento, antes do início das aulas presenciais: Como você compreende alfabetização e letramento? Quais são os prováveis ou possíveis desdobramentos desses conceitos para a sua prática profissional? Há demandas no seu local de trabalho para as quais os referidos conceitos precisam ser mobilizados? As professoras foram orientadas a responderem aos questionamentos com os saberes por elas compartilhados, sem consultas a fontes bibliográficas.

Às professoras coube pensar sobre os sentidos das questões elencadas e ponderar cuidadosamente sobre o assunto ao levantar informações acerca do tema, levando para o ambiente de sala de aula do mestrado profissional discussões/reflexões a respeito dos fenômenos da alfabetização e do letramento. Para responder algumas demandas vivenciadas e compartilhadas pelas professoras em aulas de LP, a BNCC (BRASIL, 2017) foi estudada e, considerando as recomendações do referido documento oficial, foram elaboradas atividades com encaminhamentos interdisciplinares, das quais um produto é ilustrado neste artigo, a partir de objetos de conhecimento selecionados para as aulas de LP e de ciências.

Com a experiência de ensino no ProfLetras (SILVA et al., 2017; SILVA; SOUSA; ARAÚJO, 2017), também culminando com a escrita deste artigo científico, pretendemos esclarecer que as abordagens pedagógicas da alfabetização e do letramento são necessárias em todos os componentes curriculares e em diferentes níveis de escolarização, não se restringindo ao denominado oficialmente ciclo de alfabetização: hoje delimitado entre o $1^{\circ}$ e o $3^{\circ}$ ano do ensino fundamental. Se aprovada definitivamente a proposta da BNCC (BRASIL, 2017), o ciclo se inicia ainda na educação infantil e vai até o $2^{\circ}$ ano do ensino fundamental. ${ }^{3}$

A experiência do mestrado profissional também foi justificada pelo esforço de desenvolver o letramento científico das professoras, familiarizando-as com práticas de leitura e de escrita necessárias para a produção de conhecimentos especializados em respostas a demandas

\footnotetext{
${ }^{3}$ Após a finalização e a aprovação deste artigo para publicação, foi definitivamente homologada uma versão revisada da BNCC (BRASIL, 2017) em 20 de dezembro de 2017. Neste artigo, as análises apresentadas do referido documento revelam uma etapa avançada do processo de elaboração que, após revisão, resultou no documento homologado e disponibilizado à sociedade, disponível em: <http://basenacionalcomum.mec.gov.br/abase>. Acesso em: 5 jan. 2018.
} 
nos locais de trabalho. Em outros termos, foi enfatizada a importância de se buscar novos conhecimentos nos encontros presenciais da formação continuada, a fim de que as professoras também fossem capazes de escrutinar suas próprias práticas no local de trabalho e enxergar novos caminhos e possibilidades na educação dos jovens alunos.

Este artigo está organizado em cinco principais seções, além desta introdução, das considerações finais, das referências e do anexo. Na primeira, mostramos algumas noções de alfabetização e de letramento compartilhadas pelas professoras ao relatarem experiências profissionais vivenciadas. $\mathrm{Na}$ segunda, problematizamos algumas situações de ensino exemplares da maneira como as noções teóricas mencionadas interferem ou não no trabalho pedagógico relatado. Na terceira, sintetizamos a proposta pedagógica para as aulas de LP apresentada na BNCC (BRASIL, 2017). Na quarta, mostramos como a abordagem do letramento científico informa a proposta para o ensino de ciências na mesma diretriz curricular previamente focalizada. $\mathrm{Na}$ quinta, compartilhamos uma proposta de atividade pedagógica para o estudo da LP, produzida a partir de um texto didático para aula de ciências. Apresentamos o uso de textos de outras disciplinas escolares como estratégia para contextualizar os conteúdos linguísticos a serem trabalhados em aulas de LP, resultando no encaminhamento de um trabalho interdisciplinar.

\section{$2 \mathrm{O}$ que dizem as professoras sobre alfabetização e letramento?}

Os textos das professoras revelam algumas representações a respeito do trabalho pedagógico com a escrita na escola, compreendendo alguns saberes construídos em torno dos fenômenos da alfabetização e do letramento. Mostram ainda alguns desdobramentos desses saberes nas práticas escolares de linguagem, propostas nas instituições de ensino em que as professoras atuam, bem como algumas demandas para o fortalecimento da educação dos alunos. Conforme afirmam Lüdke e André (2013, p. 45), os documentos, concebidos como fontes de pesquisa, "surgem num determinado contexto e fornecem informações sobre esse mesmo contexto".

As professoras tendem a conceber a alfabetização de forma restrita, distante, por exemplo, de uma abordagem libertadora do tipo proposta por Paulo Freire nas últimas décadas do século XX: 
entender alfabetização como a relação entre os educandos e o mundo, mediada pela prática transformadora desse mundo, que ocorre exatamente no meio social mais geral em que os educandos transitam, e mediada, também, pelo discurso oral que diz respeito a essa prática transformadora. Esse modo de compreender a alfabetização leva-me à ideia de uma alfabetização abrangente que é necessariamente política. (FREIRE, 1990, p. 56)

As professoras atribuem os resultados pouco produtivos do ensino de língua materna à supervalorização de práticas alfabetizadoras, caracterizadas por exercícios didáticos em que se enfatiza o reconhecimento de alguns aspectos do sistema da língua portuguesa, desconectados das efetivas situações de interação pela linguagem características dos inúmeros domínios sociais. Conforme veremos adiante, as professoras recorrem a abordagens do letramento para complementar a prática restrita de alfabetização.

No Exemplo 1, a escrita é representada como "código", o que para alguns estudiosos, a exemplo de Soares (2016, p. 47), é considerado um uso "impróprio". Segundo a autora, "os grafemas representam os sons da fala, e o sistema de escrita alfabético foi inventado como um sistema de representação, não como um código" (grifos da autora). ${ }^{4}$ No referido exemplo, a alfabetização é concebida como a aprendizagem das convenções da escrita, necessárias para que as crianças leiam e escrevam. O conhecimento do sistema linguístico ainda é descrito como necessário, mas não suficiente para que o leitor ou escritor possa interagir socialmente. O enunciado aponta para o fenômeno do letramento como prática social complementar.

\footnotetext{
${ }^{4}$ De acordo com Soares (2016, p. 47-48, grifos da autora), "se se considera seu significado literal, o verbo codificar denota a utilização de um sistema de sinais ou signos que substituem os grafemas do sistema alfabético, e o verbo decodificar denota, literalmente, a decifração de sinais ou signos traduzindo-os para o sistema alfabético. Assim, este, o sistema alfabético, é o sistema primeiro, não é um sistema de substituição de outro preexistente - não é um código, a não ser que se considere que os grafemas 'substituem' os sons da fala, o que não é linguisticamente verdadeiro".
} 
Exemplo 1

No processo de alfabetização, a criança adquire as habilidades de ler e escrever determinados signos linguísticos. Nessa fase, ela irá aprender os códigos específicos para todos os falantes de sua língua. Códigos esses que são uma condição necessária para que haja de fato a comunicação, no entanto, isso não é suficiente.

Da mesma forma do Exemplo 1, a alfabetização é caracterizada como a capacidade de "codificar e decodificar palavras e textos", no Exemplo 2. Nas palavras de Freire (1990, p. 56), podemos sintetizar essa concepção de alfabetização como "experiências apenas um pouco criativas, que tratam dos fundamentos das letras e das palavras como uma esfera puramente mecânica”.

\section{Exemplo 2}

significa ter domínio da leitura e da escrita, ou seja, uma pessoa alfabetizada consegue codificar e decodificar palavras e textos, é capaz de interpretar, compreender e expressar pensamentos de forma estruturada e organizada através da escrita.

Na parte final do Exemplo 2, a escrita é caracterizada, simplificadamente, como forma de expressão do pensamento ("capaz de interpretar, compreender e expressar pensamentos de forma estruturada e organizada através da escrita"), ignorando-se a concepção interativa da manifestação escrita da linguagem. ${ }^{5}$ Esse enunciado nos lembra do seguinte mito desconstruído por Tfouni (2002, p. 65), a partir de uma pesquisa desenvolvida com adultos analfabetos: "a formalização do pensamento, o raciocínio abstrato, dedutivo e descentrado" seriam consequência da "difusão social da escrita", da "adoção generalizada de um sistema (alfabético) de escrita".

\footnotetext{
${ }^{5}$ Ainda sobre a relevância da concepção de linguagem assumida em sala de aula, destacamos, nas palavras de Freire (1990, p. 76), que "a linguagem jamais deve ser compreendida como mera ferramenta de comunicação. A linguagem vem de envolta com a ideologia e, por essa razão, tem-se que lhe dar proeminência em qualquer pedagogia radical que se proponha propiciar espaço para a emancipação do aluno".
} 
Por compartilharem de noções restritas de alfabetização, que não respondem às demandas de uso da escrita fora das fronteiras da sala de aula, as professoras explicitaram noções funcionais de letramento, complementares às práticas de escrita da tradição escolar, conforme observável nos Exemplos 3 e 4.

\section{Exemplo 3}

o letramento implica na capacidade do individuo de utilizar a leitura e escrita em seu meio social, ir além de decodificar, ou seja, saber utilizar isso sendo capaz de ler e compreender, desenvolver produções textuais, e ao escrever identificar para quem está escrevendo e adequar o texto de acordo com o contexto e com os objetivos almejados.

Exemplo 4

A concepção de letramento refere-se à condição, disposição ou capacidade de que o ser humano tem para que uma vez dominada a técnica de ler e escrever - alfabetização ou alfabetismo -, possa também usá-la a fim de poder assimilar e transmitir satisfatoriamente informações, conhecimentos e cultura.

O exame das noções de letramento exemplificadas nos permite observar que as professoras encontraram nos estudos do letramento argumentos capazes de conscientizá-las da necessidade da formação de leitores e escritores ("utilizar a leitura e escrita em seu meio social, ir além de decodificar, ou seja, saber utilizar isso sendo capaz de ler e compreender, desenvolver produções textuais”), diferentemente dos alunos reprodutores de conhecimentos disciplinares cuja utilidade restringe-se às próprias práticas avaliativas da escola. Concepções de letramento desse tipo aproximam-se do discurso manifesto por Soares (2001, p. 21, grifos da autora) ao afirmar que "da mera aquisição da 'tecnologia' do ler e do escrever à inserção nas práticas sociais de leitura e escrita, [...] resultou o aparecimento do termo letramento ao lado do termo alfabetização".

O que estamos denominando de noções restritas de alfabetização está evidente no Exemplo 5: 
Exemplo 5

Sendo assim, infelizmente, a maioria de meus alunos é considerada alfabetizada e não letrada; visto que sabem ler e escrever (não perfeitamente como deveriam), mas poucas vezes conseguem compreender e interpretar, sem que antes eu tenha feito uma contextualização do conteúdo. Até mesmo nas avaliações internas, eles, às vezes, não conseguem sequer compreender o enunciado, se mudar a forma de abordagem, então... O resultado insatisfatório é quase certo.

No Exemplo 5, ilustramos o tipo de discurso recorrente nos textos investigados. Contribui para sustentar a noção de alfabetização como apropriação da prática pedagógica mecânica de leitura e de escrita, sem resultar na formação de atores sociais autônomos. Conforme explicitado no referido excerto, os alunos só conseguem compreender textos e, inclusive, enunciados de avaliações escolares com o auxilio docente. Essa noção de alfabetização é contraditória à defendida por Tfouni (2002, p. 15), que, por sua vez, é assumida neste artigo.

O mal-entendido [...] é que a alfabetização é algo que chega a um fim, e pode, portanto, ser descrita sob a forma de objetivos instrucionais. Como processo que é, no entanto, parece-me antes que o que caracteriza a alfabetização é a sua incompletude, e que a descrição dos objetivos a serem atingidos deve-se a uma necessidade de controle mais da escolarização do que da alfabetização. De fato, a alfabetização está intimamente ligada à instrução formal e às práticas escolares, e é muito difícil lidar com essas variáveis separadamente (grifo da autora).

No Exemplo 5, a noção de letramento compartilhada está alinhada a saberes do senso comum, corresponde às habilidades de compreensão/ interpretação textual, admitindo-se, inclusive, o alcance da "perfeição". Às pessoas também se possibilitaria o alcance do letramento completo, divergindo-se, mais uma vez, das teorias de referência, que caracterizam o letramento pelo aspecto processual. Também compartilhamos do seguinte argumento defendido por Tfouni (2002, p. 23): "não existe, nas sociedades modernas, o letramento 'grau zero', que equivaleria ao 'iletramento"'. A autora complementa afirmando que "do ponto de vista do processo sóciohistórico, o que existe de fato nas sociedades industriais modernas são 'graus de letramento', sem que com isso se pressuponha sua inexistência”. 
As pesquisas científicas sobre alfabetização e letramento produziram inúmeras concepções ou compreensões dos respectivos fenômenos. A diversidade de estudos nos limita o julgamento sobre possíveis correções conceptuais. Porém precisamos avaliar criticamente as noções teóricas que assumimos em função dos nossos propósitos acadêmicos ou pedagógicos.

Diante dos documentos analisados, escritos pelas professoraspesquisadoras, acreditamos na possibilidade de aprofundamento das noções de alfabetização e de letramento junto às autoras para que a formação dos alunos seja orientada por uma perspectiva mais crítica, considerando, especialmente, as relações sociais instauradas a partir de diferentes contextos socioculturais em que estão inseridos os usos da escrita, sem abrir mão de uma formação linguística consistente, possibilitando o trabalho consciente do aluno sobre a materialidade textual. Um dos grandes desafios, conforme mostraremos mais adiante, na proposição da atividade pedagógica para aula de LP, consiste no trabalho com a materialidade linguística ou, em outros termos, com a gramática da LP, no ensino fundamental. Ao expressarmos a possibilidade de avanço, consideramos o desafio enfrentado pelas profissionais para desenvolver o trabalho pedagógico a partir das próprias noções teóricas por elas compartilhadas, conforme mostramos na seção seguinte deste artigo.

\section{$3 \mathrm{O}$ que dizem as professoras sobre as práticas escolares?}

A análise dos escritos docentes revelou que seis professoras não apresentaram nenhuma contribuição ou desdobramento da abordagem do letramento na própria prática pedagógica. Das nove professoras que apresentaram desdobramentos da abordagem do letramento em sala de aula, sete demonstraram insatisfação com os resultados, ao passo que apenas duas demonstram alguma satisfação com os resultados alcançados.

A forma como a abordagem do letramento aparece nas aulas de LP fica evidente quando as professoras relatam esforços despendidos para alcançar resultados produtivos na educação dos alunos, conforme mostra o Exemplo 6. As atividades pedagógicas ("dramatizações"; "pesquisas"; "apresentações teatrais") e os recursos didáticos ("livros literários"; "vídeos"; "músicas"; "gêneros textuais digitais"; "pequenos textos") são utilizados com o propósito de proporcionar uma maior familiarização dos alunos com práticas de leitura e de escrita. 
Exemplo 6

Entendendo que meus alunos possuem carência de leitura e escrita, procuro desenvolver atividades utilizando livros literários, revistas, vídeos, músicas, dramatizações, pesquisas - no simplório laboratório de informática - de gêneros textuais digitais, de pequenos textos, em sala de aula, utilizando os recursos tecnológicos disponíveis, e, também, em apresentações teatrais bimestrais nas dependências da escola, envolvendo as datas comemorativas. Mas sinto que uma parte significativa desses alunos apresenta muita resistência/dificuldade quando vão externar, oralmente e por escrito, o que assimilaram nas atividades propostas e executadas no decorrer das aulas.

No texto do Exemplo 6, a professora informa que os alunos possuem bastante dificuldade nas práticas de leitura e de escrita. Talvez esse fato e o comando da atividade solicitada pelo formador justifiquem a ênfase textual nessas práticas escolares de linguagem mais diversas, desconsiderando o trabalho metalinguístico característicos das aulas de LP. O texto focalizado corresponde a uma das ocorrências em que a professora demonstra insatisfação com os resultados produzidos a partir dos esforços despendidos. A insatisfação docente é sinalizada pelo operador argumentativo de contrajunção "mas" ("Mas sinto que uma parte significativa desses alunos apresenta muita resistência/dificuldade quando vão externar, oralmente e por escrito, o que assimilaram nas atividades propostas e executadas no decorrer das aulas").

O Exemplo 7 revela resultados satisfatórios das práticas escolares de linguagem propostas em função das dificuldades demonstradas pelos alunos no tocante às práticas de leitura e de escrita. Mais uma vez, estratégias pedagógicas diferenciadas, justificadas pela demanda de maior comprometimento dos alunos e, possivelmente, caracterizadas pela redução da reprodução de saberes disciplinares, motiva a participação dos jovens aprendizes. 
Exemplo 7

Cito como exemplo a escola onde trabalho, considerada escola do campo, onde estudam somente alunos que vivem em fazendas, chácaras ou sítios. Há vários alunos com dificuldades na questão de leitura, escrita e interpretação de textos, porém, sempre observo que nas apresentações, todos participam ativamente, fazem dramatizações, cantam, dançam, criam paródias com temas atuais. Observo ainda que a maior parte deles utiliza o celular com certa desenvoltura, criam grupos, compartilham diversas coisas e numa disciplina específica chamada Saberes e Fazeres do Campo, eles expõem com clareza as atividades que participam em casa, relacionadas à agricultura e à pecuária.

Ao reconhecer o desempenho satisfatório discente em situações de aprendizagem envolvendo o contexto sociocultural dos alunos ("Saberes e Fazeres do Campo"), a professora aponta para as dimensões sociais do letramento. As práticas escolares de linguagem ganham especificidades locais, evitando-se o trabalho restrito a objetos de conhecimento genéricos, cuja seleção parece se justificar apenas pelo valor simbólico construído historicamente.

O relato do Exemplo 7 nos remete indiretamente a algumas estratégias de ensino sugeridas em diretrizes oficiais, a exemplo do encaminhamento apresentado na BNCC (BRASIL, 2017), que será focalizada mais diretamente em seções posteriores deste artigo. $\mathrm{Na}$ área de Ciências Humanas do referido documento, encaminham-se a valorização e a problematização das "vivências e experiências individuais e familiares trazidas pelos alunos, por meio do lúdico, de trocas, da escuta e de falas sensíveis, nos diversos ambientes educativos (bibliotecas, pátio, praças, parques, museus, arquivos, entre outros)" (BRASIL, 2017, p. 307). Tais orientações com propósito de estímulo à pesquisa na escola estão alinhadas às recomendações das demais áreas do conhecimento (Linguagens; Matemática; Ciências da Natureza).

A escola precisa fortalecer os alunos para responderem às demandas interativas locais, mediadas pela tecnologia da escrita, o que não significa ignorar o trabalho de familiarização dos alunos com usos da escrita característicos de outros domínios ou contextos socioculturais. Os objetos de conhecimento da tradição escolar não podem se sobrepor à formação 
crítica dos discentes. Essa última envolve os usos das práticas de leitura e de escrita como formas de compreensão e ação sobre o mundo.

\section{O que é dito na BNCC sobre o ensino de língua portuguesa?}

A BNCC (BRASIL, 2017) foi elaborada com objetivo de garantir os conteúdos disciplinares comuns a serem trabalhados em todas as escolas brasileiras de educação infantil e ensino fundamental, sendo este último focalizado mais diretamente neste artigo. No documento, idealiza-se que os alunos matriculados em todas as escolas de ensino básico, nas cinco regiões geográficas brasileiras, tenham acesso aos mesmos componentes curriculares (disciplinas escolares), a partir da indicação de objetos de conhecimento (conteúdos disciplinares) e de habilidades a serem trabalhadas ao longo da escolaridade. Ressaltamos que, na BNCC (BRASIL, 2017), é esclarecido o que os estudantes devem aprender e não como ensiná-los. As estratégias de ensino ficam a cargo dos profissionais da educação na escola básica e, de forma mais enriquecedora, desejamos que sejam assumidas e elaboradas em parceria com os formadores de professores nas universidades.

Com as recomendações para o componente curricular de LP, objetiva-se "garantir a todos os alunos o acesso aos saberes linguísticos necessários para a participação social e o exercício da cidadania” (BRASIL, 2017, p. 63). A linguagem é o pressuposto necessário para que as pessoas sejam capazes de elaborar pensamentos, comunicar-se, acessar os mais diversos tipos de informações e produzir conhecimentos. Considerando o texto como o "centro das práticas de linguagem", os objetos de conhecimento para o ensino de LP estão organizados em cinco eixos, conforme sistematizamos na Figura 1: 
FIGURA 1 - Eixos organizadores do ensino de LP

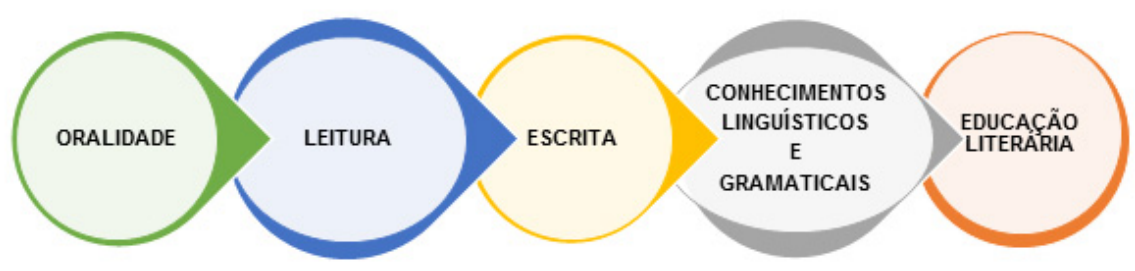

Fonte: Elaborada a partir da BNCC (BRASIL, 2017, p. 63-65).

Cada eixo está organizado em unidades temáticas, que, por sua vez, estão atrelados a objetos de conhecimento e habilidades. Neste artigo, focalizamos mais diretamente os eixos de leitura e de conhecimentos linguísticos e gramaticais, os quais foram considerados na elaboração da atividade pedagógica apresentada ao final do artigo.

A leitura é concebida como instrumento para todos os componentes curriculares, sendo tema central nas aulas de LP. O eixo de práticas de leitura envolve a decifração de palavras e textos, visando ao desenvolvimento das habilidades de compreensão e interpretação textual (BRASIL, 2017). As noções teóricas de gênero textual ou discursivo podem ser mobilizadas para auxiliar as práticas de leitura, uma vez que as convenções socioculturais de organização ou configuração textual servem como elementos metagenéricos, ou seja, como pistas para a construção de sentidos para os textos.

A proposta da BNCC (BRASIL, 2017) para o eixo de leitura se aproxima dos conceitos de alfabetização e de letramento propostos por Soares $(2001,2016)$. A primeira é compreendida como a aprendizagem dos sistemas alfabético, ortográfico e gramatical da língua portuguesa e o segundo como práticas sociais de leitura e de escrita. A proveitosa utilização da escrita e da leitura em diferentes domínios sociais demanda o aprendizado das convenções dos sistemas linguísticos necessários à escrita da LP (alfabetização) que, por sua vez, realiza-se em "eventos de letramento", compreendidos como situações interativas cotidianas em que a escrita exerce alguma função (HEATH, 1983).

O documento focalizado considera a alfabetização e o letramento como processos interdependentes, sendo, portanto, apreendidos 
simultaneamente: "o letramento é condição para a alfabetização, para o domínio das correspondências entre grafemas e fonemas, mas a alfabetização e a exploração sistemática dessas relações grafofonêmicas são também condição para o letramento" (BRASIL, 2017, p. 69).

Nos anos finais do ensino fundamental, as estratégias de compreensão e interpretação saltam a um nível mais elevado de exigências cognitivas, bem como em quantidade, ampliando assim, também, o nível de complexidade dos textos (BRASIL, 2017). As práticas de compreensão e interpretação de diferentes linguagens devem ocorrer a partir de textos da atualidade, nos quais deve ser observada a adequação de temas e de assuntos à faixa etária dos alunos.

A título de exemplo, a unidade temática construção da autonomia de leitura visa ao desenvolvimento das habilidades leitoras, capazes de tornar o aluno um leitor autônomo, considerando, inclusive, diferentes manifestações de linguagens características dos domínios sociais situados fora dos muros da escola. Nesse ponto, a proposta da BNCC (BRASIL, 2017) dialoga com as teorias de letramentos sociais, a exemplo da proposta de Street (2014). Porém o documento não apresenta mecanismos metodológicos para evitar a excessiva escolarização do letramento. Para o autor, escolarização ou pedagogização do letramento diz respeito à associação deste à sistematização da educação e às atividades vivenciadas no contexto da sala de aula, desconsiderando os usos e significados dos letramentos fora do ambiente escolar.

Os objetos de conhecimento apresentados na BNCC (BRASIL, 2017) podem proporcionar aos alunos habilidades leitoras e reflexivas, as quais servirão de ferramentas ou suportes para que eles sejam capazes de ler e compreender textos multimodais moldados por diversos gêneros, familiarizando-os com diferentes eventos de letramento, integrando-os, por sua vez, às rotinas dos jovens aprendizes.

O eixo dos conhecimentos linguísticos e gramaticais envolve, nos anos iniciais do ensino fundamental, o processo de alfabetização, cujo ciclo deve ser finalizado no $2^{\circ}$ ano. A alfabetização deve ser iniciada no final da educação infantil e continuar nos dois anos iniciais do ensino fundamental. Os anos seguintes devem proporcionar o aprofundamento do conhecimento dos sistemas ortográficos e gramaticais, conforme sintetizamos no Quadro 1. 
QUADRO 1 - Síntese da proposta do eixo conhecimentos linguísticos e gramaticais

\begin{tabular}{|c|c|c|}
\hline Unidades temáticas & Objetos de conhecimentos & Anos escolares \\
\hline \multirow{5}{*}{$\begin{array}{l}\text { Apropriação do sistema } \\
\text { alfabético de escrita }\end{array}$} & Compreensão do sistema alfabético de escrita & $1^{\circ}$ \\
\hline & Consciência fonológica & $1^{\circ}$ \\
\hline & Consciência grafofonêmica & $1^{\mathrm{o}} ; 2^{\mathrm{o}} ; 3^{\mathrm{o}} ; 4^{\mathrm{o}}$ \\
\hline & Conhecimento do alfabeto & $1^{\mathrm{o}} ; 2^{\mathrm{o}}$ \\
\hline & Consciência silábica & $2^{\circ}$ \\
\hline Convenções gráficas da escrita & Segmentação de palavras & $1^{\circ}$ \\
\hline \multirow{6}{*}{$\begin{array}{l}\text { Processos de formação e } \\
\text { significados das palavras }\end{array}$} & Sinonímia e antonímia & $1^{\circ} ; 2^{\circ} ; 6^{\circ}$ \\
\hline & Aumentativo e diminutivo & $2^{\circ}$ \\
\hline & Derivação prefixal e sufixal & $3^{\circ}$ \\
\hline & Derivação sufixal & $3^{\circ}$ \\
\hline & Polissemia & $5^{\circ}$ \\
\hline & Derivação e composição & $5^{\circ} ; 6^{\circ} ; 7^{\circ} ; 8^{\circ}$ \\
\hline \multirow{6}{*}{ Ortografia } & Estruturas silábicas & $2^{\circ} ; 3^{\circ}$ \\
\hline & Pontuação & $2^{\mathrm{o}} ; 3^{\mathrm{o}} ; 4^{\mathrm{o}} ; 5^{\mathrm{o}}$ \\
\hline & Uso do dicionário & $3^{\circ} ; 4^{\circ}$ \\
\hline & Acentuação & $3^{o} ; 4^{o} ; 5^{\circ}$ \\
\hline & Consciência grafofonêmica & $5^{\circ}$ \\
\hline & Regras ortográficas & $6^{\circ} ; 7^{\circ}$ \\
\hline
\end{tabular}




\begin{tabular}{|c|c|c|}
\hline \multirow{19}{*}{ Morfossintaxe } & Funções sintáticas do substantivo e do verbo & $3^{\circ}$ \\
\hline & Funções sintáticas do adjetivo & $3^{\circ}$ \\
\hline & Processos de coesão & $3^{\circ} ; 4^{\circ} ; 7^{\circ}$ \\
\hline & Aposto e vocativo & $4^{\circ}$ \\
\hline & Concordância verbal & $4^{\mathrm{o}} ; 5^{\mathrm{o}} ; 6^{\mathrm{o}} ; 7^{\mathrm{o}}$ \\
\hline & Concordância nominal & $4 ; 5 ; 6 ; 7$ \\
\hline & Tempos verbais & $5^{\circ}$ \\
\hline & Conjunção & $5^{\circ}$ \\
\hline & $\begin{array}{l}\text { Flexões do substantivo, do adjetivo e dos verbos } \\
\text { regulares }\end{array}$ & $6^{\circ}$ \\
\hline & Modos verbais & $6^{\circ}$ \\
\hline & Estrutura da frase & $6^{\circ}$ \\
\hline & Oração e período & $6^{\circ} ; 7^{\circ} ; 8^{\circ}$ \\
\hline & Estrutura da oração & $6^{\circ} ; 7^{\circ} ; 8^{\circ}$ \\
\hline & Pontuação & $6^{\circ}$ \\
\hline & Regência verbal & $8^{\circ} ; 9^{\circ}$ \\
\hline & Vozes verbais & $8^{\circ}$ \\
\hline & Regência nominal & $9^{\circ}$ \\
\hline & Colocação pronominal & $9^{\circ}$ \\
\hline & $\begin{array}{l}\text { Marcas da relação entre as orações no período } \\
\text { composto: orações subordinadas }\end{array}$ & $9^{\circ}$ \\
\hline
\end{tabular}

Fonte: Produzido a partir da BNCC (BRASIL, 2017).

Neste artigo, não apresentamos uma análise exaustiva dos objetos de conhecimento elencados ao longo dos anos escolares e distribuídos em cinco unidades temáticas (Apropriação do sistema alfabético de escrita; Convenções gráficas da escrita; Processos de formação e significados das palavras; Ortografia; Morfossintaxe). Destacamos, porém, um aspecto do eixo focalizado que poderá causar, minimamente, algum estranhamento por parte das professoras de LP, no ensino fundamental.

Diferentemente das diretrizes curriculares nacionais vigentes, Parâmetros Curriculares Nacionais - PCN (BRASIL, 1997, 1998), a terminologia gramática é explicitamente utilizada na BNCC (BRASIL, 
2017). ${ }^{6}$ Em contraposição à concepção de gramática, que, quase sempre, remete a abordagens normativas ou prescritivas da língua, nos PCN (BRASIL, 1997, 1998), foi assumida a proposta de análise linguística. Essa proposta também é defendida em pesquisas científicas realizadas nos estudos linguísticos, não significando simplesmente uma troca de nomenclaturas (APARÍCIO, 2010; FRANCHI, 2006; SILVA, 2011). Um dos propósitos dos PCN (BRASIL, 1997, 1998) era distanciar as professoras das práticas pedagógicas características do ensino de LP, marcadas por exercícios metalinguísticos descontextualizados, os quais pouco contribuíam para a formação de alunos leitores ou escritores (NEVES, 1999; SILVEIRA, 2016).

A observação atenta dos objetos de conhecimento distribuídos ao longo dos anos escolares, conforme síntese reproduzida no Quadro 1, revela um evidente risco de retrocesso no ensino do português como língua materna nas escolas brasileiras. A ausência de propostas ou encaminhamentos metodológicos na BNCC (BRASIL, 2017) corrobora o risco mencionado.

A título de ilustração, destacamos as principais formas verbais utilizadas para introduzir as habilidades a serem desenvolvidas para os objetos de conhecimento elencados, especialmente nas unidades temáticas Processos de formação e significados das palavras e Morfossintaxe: "identificar"; "reconhecer"; "definir"; "classificar"; "distinguir". Essas formas verbais apontam exatamente para as práticas pedagógicas da tradição escolar, quando os alunos são levados a identificar, classificar e definir categorias gramaticais, resultando, inclusive, no fracasso dessas próprias práticas. O trabalho escolar com a gramática da língua portuguesa não tem garantido aos alunos habilidades de reflexão consciente sobre o funcionamento das formas gramaticais em textos moldados por gêneros diversos (SILVA, 2011, 2012; SILVEIRA, 2016).

Para as demais unidades temáticas (Apropriação do sistema alfabético de escrita; Convenções gráficas da escrita; Ortografia), as habilidades as serem desenvolvidas são introduzidas por outras formas verbais ("ler"; "escrever"; "memorizar"; "usar"; "flexionar"; "analisar"; "empregar"), que apontam para práticas de uso e de reflexão sobre o sistema linguístico do português brasileiro. Essas últimas formas verbais

\footnotetext{
${ }^{6}$ Esclarecemos que os PCN (BRASIL, 1997, 1998) e a BNCC (BRASIL, 2017) são documentos oficiais produzidos com propósitos diferenciados, portanto a aprovação desse último não significará substituição dos primeiros.
} 
aqui mencionadas aparecem em número mais reduzido nas habilidades descritas na BNCC (BRASIL, 2017).

Conforme também proposto nos PCN (BRASIL, 1997, 1998), espera-se que o estudo do que, hoje, é denominado de conhecimentos linguísticos e gramaticais aconteça articulado aos demais eixos de práticas escolares de linguagem, os quais foram desdobrados na BNCC (BRASIL, 2017), garantindo, sobretudo, maior visibilidade ao trabalho pedagógico com a educação literária. Certamente, diante da lista posta de objetos de conhecimento a serem trabalhados em sala de aula, tal articulação demandada se configurará como o maior desafio para as professoras da escola básica, egressas das licenciaturas em Letras e, sobretudo, em Pedagogia.

\section{$5 \mathrm{O}$ que é dito na BNCC sobre o ensino de ciências?}

Para que o cidadão seja considerado cientificamente alfabetizado ou, até mesmo, letrado, pressupõe-se que seja familiarizado com usos da escrita característicos das atividades interativas em torno da produção, circulação ou consumo de conhecimentos científicos. A conscientização crítica das pessoas no tocante aos impactos da ausência ou da presença da produção científica e tecnológica na sociedade também informa as especificidades da alfabetização e do letramento tematizados nesta seção.

Sem pretensão de aprofundamento da questão neste artigo, compreendemos ciências como atividades investigativas e criativas de produção de saberes ou tecnologias em disciplinas ou campos do conhecimento que também estão situados fora das fronteiras das denominadas ciências naturais, onde encontramos, por exemplo, as ciências das linguagens. Não ignoramos a possibilidade de produção de ciência por não especialistas, ou seja, por cidadãos comuns que, por alguma razão, não transitaram pelos espaços acadêmicos (DEMO, 2010; SANTOS, 2010).

A noção de letramento científico informa as propostas pedagógicas de diferentes componentes curriculares na BNCC (BRASIL, 2017) e, de forma bastante elaborada, em ciências. No campo investigativo do ensino de ciências, dentro e fora do território brasileiro, consolida-se uma produção significativa de pesquisas sobre alfabetização científica ou letramento científico (AKDUR, 2009; CHASSOT, 2014; CUNHA, 2017; SANTOS, 
2007), o que, no contexto brasileiro dos estudos das linguagens, encontra-se num estágio ainda embrionário (SILVA, 2016).

Para o ensino fundamental, os saberes produzidos na biologia, física e química foram reunidos na BNCC (BRASIL, 2017) sob a denominação de ciências. No referido documento, busca-se garantir que os alunos sejam expostos a conhecimentos que garantam aos mesmos a capacidade de:

Debater e tomar posição sobre alimentos, medicamentos, combustíveis, transportes, comunicações, contracepção, saneamento e manutenção da vida na Terra, entre muitos outros temas, são imprescindíveis tanto conhecimentos éticos, políticos e culturais quanto científicos. Isso por si só já justifica, na educação formal, a presença da área de Ciências da Natureza, e de seu compromisso com a formação integral dos alunos. (BRASIL, 2017, p. 273)

Para Santos (2007), aprender ciência também significa compreender como os cientistas trabalham e quais as limitações de seus conhecimentos. Isso implica conhecimentos sobre história, filosofia e sociologia da ciência. Na BNCC (BRASIL, 2017, p. 273) é recomendado, ao longo do ensino fundamental, que a área de Ciências da Natureza comprometa-se "com o desenvolvimento do letramento científico, que envolve a capacidade de compreender e interpretar o mundo (natural, social e tecnológico), mas também de transformá-lo com base nos aportes teóricos e processuais da ciência".

Essa proposição se materializa a partir da recomendação da elaboração de um componente curricular que garanta aos alunos o acesso à diversidade de conhecimentos científicos já produzidos, aproximandoos dos "processos, práticas e procedimentos de investigação científica" (BRASIL, 2017, p. 273). Espera-se que, durante essa etapa educacional, os alunos passem a ter uma nova visão do mundo em que estão inseridos e, consequentemente, possam fazer escolhas e intervenções com base em princípios sustentáveis e altruístas. Para orientar a elaboração dos currículos escolares, os objetos de conhecimento assegurados pelo componente focalizado foram organizados em três unidades temáticas ao longo do ensino fundamental, sem a organização por eixos: Matéria e energia; Vida e evolução; Terra e Universo.

Em síntese, destacamos, de acordo com a BNCC (BRASIL, 2017), que o ensino de ciências deve oportunizar a inserção dos alunos em 
contextos sociais que lhes proporcionem a vivência de momentos de investigação científica, exercitação e ampliação da curiosidade, além do aperfeiçoamento da capacidade de observação, do raciocínio lógico e de criação, desenvolvendo posturas mais colaborativas e sistematizadas de suas primeiras explicações sobre o mundo natural, tecnológico e cuidados sobre o próprio corpo, saúde e bem-estar. A formação do indivíduo com autonomia de pensamento alicerça tais orientações oficiais e, como afirma Demo (2010, p. 9), "saber pensar passou a ícone da aprendizagem bem-sucedida: a maior glória de um professor é inventar um aluno que sabe pensar".

Percebemos ainda uma relação próxima entre tais proposições e algumas contribuições filosóficas de Michel Foucault (2017), quando o autor discorre sobre a relevância da ética, da responsabilidade e do cuidado de si mesmo - empreendedor de si -, que cada ser humano deve ter, visando ao uso da liberdade de modo consciente ou sustentável. Essa postura reflete diretamente no bem-estar comum dos cidadãos, do convívio social com o intuito de construir cooperativamente um mundo mais justo de oportunidades e igualdade.

\section{Que atividade pedagógica pode ser proposta?}

Conforme depreendemos da análise dos textos das professoraspesquisadoras, as dificuldades enfrentadas pelos alunos para compreender e escrever textos se configuram como os grandes desafios para as escolas de ensino básico. Considerando a ausência de encaminhamentos metodológicos precisos na BNCC (BRASIL, 2017), vislumbramos a elaboração de uma atividade pedagógica com encaminhamento interdisciplinar. Foi produzida a partir de objetos de conhecimento recomendados para aulas de LP e ciências, no $6^{\circ}$ ano do ensino fundamental. A atividade exemplificada adiante também pode ser utilizada com turmas de escolaridade mais avançada, pois bem sabemos das adversidades enfrentadas por escolas brasileiras, o que faz inúmeros alunos demonstrarem desempenho bastante diferenciado no mesmo ano de escolaridade. No Quadro 2 reproduzimos os objetos de conhecimento focalizados na atividade a partir dos eixos leitura e conhecimentos linguísticos e gramaticais. 
QUADRO 2 - Objetos de conhecimento selecionados em LP ( $6^{\circ}$ ano)

Eixo Leitura - Práticas de compreensão e interpretação de textos verbais, verbo-visuais e multimodais. Textos da atualidade, com assunto e tema apropriados à faixa etária dos alunos e nível de textualidade adequado: vocabulário com possibilidades de enriquecimento do léxico do aluno e recursos expressivos denotativos e conotativos.

\begin{tabular}{l|l|l}
\hline \multicolumn{1}{c|}{ Unidade temática } & Objeto de conhecimento & \multicolumn{1}{c}{ Habilidade } \\
\hline Estratégias de leitura & $\begin{array}{l}\text { Localização de informações em } \\
\text { textos }\end{array}$ & $\begin{array}{l}\text { (EF06LP07) Localizar e hierarquizar } \\
\text { informações em textos. }\end{array}$ \\
\hline
\end{tabular}

Eixo Conhecimentos linguísticos e gramaticais - Práticas de análise linguística e gramatical (como estratégia para o desenvolvimento produtivo das práticas de oralidade, leitura e escrita). Reflexão sobre os usos do léxico e de regularidades no funcionamento da língua falada e escrita.

\begin{tabular}{l|l|l}
\hline \multicolumn{1}{c|}{ Unidade temática } & Objeto de conhecimento & Habilidade \\
\hline Morfossintaxe & Estrutura da frase & $\begin{array}{l}\text { (EF06LP32) Identificar, em texto } \\
\text { ou sequência textual, orações como } \\
\text { unidades constituídas em torno de } \\
\text { um núcleo verbal e períodos como } \\
\text { conjunto de orações conectadas. }\end{array}$ \\
\hline
\end{tabular}

Fonte: BNCC (BRASIL, 2017, p. 116-117, 122-123).

A respeito do trabalho com conteúdo gramatical em aulas de LP, a abordagem do letramento científico pode se configurar em estratégias metodológicas produtivas para o estudo dos sistemas linguísticos a partir de práticas de pesquisa na escola, incentivando o pensamento crítico e questionador dos alunos, conforme experiência relatada em Reis (2016).

A atividade foi elaborada a partir de um texto didático com exposição de conteúdos atrelados às aulas de ciências. Isso possibilita à professora do referido componente curricular desenvolver um trabalho mais sistematizado sobre "forma" e "estrutura da Terra", objeto de conhecimento selecionado em ciências, conforme reproduzido no Quadro 3: 
QUADRO 3 - Objetos de conhecimento selecionados em ciências ( $6^{\circ}$ ano)

\begin{tabular}{l|l|l}
\hline \multicolumn{1}{c|}{ Unidade temática } & Objeto de conhecimento & \multicolumn{1}{c}{ Habilidade } \\
\hline Terra e Universo & $\begin{array}{l}\text { Forma, estrutura e } \\
\text { movimentos da Terra }\end{array}$ & $\begin{array}{l}\text { (EF06CI11) Identificar as diferentes camadas que } \\
\text { estruturam o planeta Terra (da estrutura interna à } \\
\text { atmosfera) e suas principais características. }\end{array}$ \\
\hline
\end{tabular}

Fonte: BNCC (BRASIL, 2017, p. 296-297).

O texto de referência da atividade pedagógica, reproduzido no anexo deste artigo, foi selecionado pelas professoras-pesquisadoras na página eletrônica Brasil Escola (UOL), que disponibiliza conteúdos educativos passíveis de uso, especialmente, por profissionais da educação e, até mesmo, por alunos. Uma das formas de organização dos conteúdos na página é por disciplinas, onde o texto selecionado está disponível no espaço reservado à Geografia, sendo assinado por um geógrafo. Essa informação evidencia como os materiais compartilhados atravessam os frágeis limites das disciplinas do conhecimento. Como resultado da estratégia pedagógica das professoras, o texto passou a ser unidade de análise na aula de LP, também podendo contribuir para o trabalho com objetos de conhecimento em aulas de ciências.

O texto selecionado contribui para o desenvolvimento de práticas de leitura, especialmente pelo caráter pedagógico e multimodal. A natureza do texto pode ser questionada, uma vez que se trata de uma produção textual com fins pedagógicos. Não podemos esquecer, porém, que os alunos precisam ser preparados para os gêneros ou práticas de leitura característicos dos diferentes componentes curriculares, afinal é comum ouvirmos professoras afirmarem que os alunos não aprendem os objetos de conhecimento trabalhados em sala de aula porque não compreendem os textos lidos.

Inicialmente, as professoras sugerem que, antes de disponibilizar as questões elaboradas, os alunos sejam orientados a identificar os conteúdos tematizados em cada parágrafo, de maneira que possam compreender como as informações foram organizadas na materialidade textual. Posteriormente, as professoras orientam que os alunos relacionem o esquema explicativo das camadas da Terra, disponibilizado em forma de figura no centro do texto, à organização do assunto tematizado em cada parágrafo.

Essas orientações preliminares se mostram produtivas, pois excetuando os parágrafos introdutório, conclusivo e de apresentação do esquema explicativo, cada parágrafo é destinado à descrição de um tipo 
de camada da terra, na mesma sequência em que as referidas camadas são dispostas na figura. $\mathrm{O}$ uso do negrito para identificar as camadas terrestres também auxilia na localização das informações no texto, objeto de conhecimento selecionado no eixo de leitura.

Há estudos científicos que propõem o uso de ferramentas pedagógicas, a exemplo de projetos interdisciplinares ou de letramento, e sequências ou unidades didáticas, para organizar o trabalho com diferentes objetos de conhecimento, em abordagens críticas do tipo a dos estudos do letramento (DOLZ; GAGNON; DECÂNDIO, 2010; SILVA, 2015).7 Assim, os eixos organizadores do ensino podem ser trabalhados articuladamente a partir de atividades modelares de diversas práticas sociais. A atividade aqui exemplificada pode ser contextualizada nessas ferramentas, o que não desmerece o uso isolado da atividade em aula, haja vista que o planejamento escolar nem sempre se efetivará nas referidas ferramentas pedagógicas.

Neste artigo, nosso enfoque recai precisamente em questões de leitura e de conhecimento linguístico/gramatical. Elas integram respectivamente as duas partes da atividade pedagógica. Esta última é apresentada como um exemplo produtivo para o trabalho com os objetos de conhecimento selecionados e, portanto, legitimados na BNCC (BRASIL, 2017). Considerando o histórico das aulas de LP, se não forem cuidadosamente trabalhados, esses conteúdos podem significar um retrocesso para o ensino da língua materna no contexto brasileiro, conforme já destacamos previamente.

\footnotetext{
${ }^{7}$ Nesse assunto, Fidelis, Martins e Ribeiro (UFT) desenvolvem suas dissertações de mestrado profissional:

FIDELIS, A. C. Proposta de ressignificação de práticas escolares de linguagem pela abordagem do letramento científico no ciclo de alfabetização. Dissertação (Mestrado Profissional em Letras) Programa de Pós-Graduação em Letras, Universidade Federal do Tocantins, Araguaína. Trabalho em andamento.

MARTINS, J. M. Letramento científico a partir de textos propagandísticos em aulas de Lingua Portuguesa no ensino fundamental. Dissertação (Mestrado Profissional em Letras) - Programa de Pós-Graduação em Letras, Universidade Federal do Tocantins, Araguaína. Trabalho em andamento.

RIBEIRO, M. H. C. Aulas de Lingua Portuguesa e de Geografia mediadas pela abordagem do letramento científico: história do espaço geográfico de Juarina reconstruída por alunos da escola básica. Dissertação (Mestrado Profissional em Letras) - Programa de Pós-Graduação em Letras. Universidade Federal do Tocantins, Araguaína. Trabalho em andamento.
} 
Conforme observável no Exemplo 8, as questões de leitura demandam respostas objetivas disponíveis no texto de referência, sendo possível sua apresentação a partir da cópia de passagens do texto focalizado. As questões foram motivadas pelo próprio gênero cujo propósito corresponde à exposição de conteúdos disciplinares para a instrução discente. Contribuem para o alcance da habilidade de "localizar e hierarquizar informações em textos", conforme proposto na BNCC (BRASIL, 2017, p. 117).

\section{Exemplo 8}

\section{PARTE I - LEITURA}

De acordo com o texto lido, responda as perguntas seguintes:

1. Como é definida a estrutura interna da terra?

Resposta sugerida: A estrutura interna da Terrae é toda a composição do planeta formada pela superficie e tudo o que se encontra abaixo da referida superfície. É formada por várias formas, temperaturas, aspectos e composições químicas.

2. Quantas camadas compõem o planeta terra?

Resposta sugerida: O planeta possui três principais camadas e duas descontinuidades. Essas últimas são as estruturas encontradas entre uma camada e outra.

3. Quais são as três principais camadas da terra?

Resposta sugerida: As três principais camadas da terra são: Crosta terrestre, Manto e Núcleo.

4. Circule os elementos que compõem a crosta terrestre. silício magma alumínio ferro níquel magnésio

5. A espessura da crosta terrestre varia dependendo da sua localização. Qual é a maior espessura que a crosta terrestre pode atingir e em que localização isso ocorre?

Resposta sugerida: A maior espessura que a crosta terrestre pode atingir é de 70 km. Isso só pode ocorrer nas zonas continentais.

Conforme mostrado no Quadro 1, a BNCC (BRASIL, 2017) determina que a morfossintaxe do verbo seja trabalhada entre o $3^{\circ}$ e $6^{\circ}$ ano, objetivando o alcance de habilidades como: "(EF03LP30) Identificar e diferenciar, em textos, substantivos e verbos e suas funções na frase: sujeito, 
predicado, objeto direto (BRASIL, 2017, p. 93)" e "(EF05LP34) Identificar a expressão de presente, passado e futuro em tempos verbais do modo indicativo (BRASIL, 2017, p. 113)". Nesse sentido, na segunda parte da atividade pedagógica, Exemplo 9, consideramos que os alunos já possuem algum conhecimento linguístico sobre as formas verbais. O conhecimento dessa classe gramatical é necessário para o enfoque da "estrutura da frase", objeto de conhecimento selecionado para a atividade.

\section{Exemplo 9}

\section{PARTE II - CONHECIMENTOS LINGUÍSTICOS E GRAMATICAIS}

1. Leia atentamente o quinto parágrafo do texto reproduzido abaixo e responda as duas questões seguintes que retomam a classe gramatical dos verbos, estudada previamente.

"A segunda camada da Terra é o Manto. Este apresenta profundidades que vão dos $30 \mathrm{~km}$ abaixo da superfície até $2.900 \mathrm{~km}$, além de temperaturas internas que chegam a alcançar os $2.000^{\circ} \mathrm{C}$, o que propicia o derretimento das rochas, transformando-as em magma. No manto interno, o material é mais líquido, haja vista que as temperaturas $\underline{\text { são }}$ maiores; já no manto externo o material magmático é mais pastoso".

a) Identifique todas as formas verbais no parágrafo selecionado e apresente-as na forma nominal do infinitivo.

Resposta sugerida: ser; apresentar; ir; chegar; alcançar; propiciar; transformar.

b) Observe a definição de verbo, apresentada pelo gramático Evanildo Bechara e responda o questionamento seguinte:

"unidade que significa ação ou processo, unidade esta organizada para expressar o modo, o tempo, a pessoa e o número" (BECHARA, 2010, p. 192).

Considerando as formas verbais identificadas no parágrafo selecionado, podemos afirmar que essas palavras significam "ação" ou "processo", conforme afirmado pelo gramático?

Resposta sugerida: Alguns verbos utilizados no parágrafo contribuem diretamente para descrever o manto terrestre, portanto não significam ação ou processo: ser; apresentar; ir. Os outros verbos, de alguma forma, significam ação ou processo, mas também contribuem para a caracterização do manto terrestre. A descrição é colaborada também pelo uso das formas verbais no presente do modo indicativo. 
Observe os dois enunciados seguintes selecionados do texto:

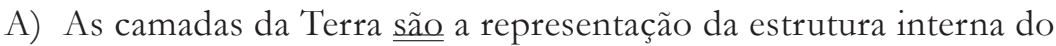
nosso planeta.

B) Ela encontra-se totalmente em estado líquido e apresenta temperaturas maiores que as do manto.

Em A, foi utilizado apenas um verbo flexionado (ser). O verbo flexionado é chamado de núcleo da construção gramatical.

Por possuir apenas um verbo flexionado, podemos denominar A de ORAÇÃO GRAMATICAL.

Em B, foram utilizados dois verbos flexionados (encontrar, apresentar). Portanto há duas ORAÇÕES GRAMATICAIS em B:

Ela encontra-se totalmente em estado líquido

e

apresenta temperaturas maiores que as do manto.

Observe ainda:

A construção gramatical com UMA ORAÇÃO recebe o nome de: PERÍODO SIMPLES.

A construção gramatical com MAIS DE UMA ORAÇÃO recebe o nome de: PERÍODO COMPOSTO.

2. No texto lido, há cinco parágrafos utilizados para descrever individualmente as cinco camadas da terra. Os parágrafos são distribuídos no texto na mesma sequência em que as camadas aparecem na figura. Identifique esses parágrafos.

Resposta sugerida: São os terceiro, quarto, quinto, sexto e sétimo parágrafos. 
3. Em cada um dos parágrafos identificados na questão anterior, há um período simples (formado por uma única oração gramatical) que descreve a localização da camada terrestre. Primeiro, identifique esses períodos, em seguida, explique o que há em comum entre os usos desses períodos nos cinco parágrafos identificados em relação à organização das informações no texto.

Resposta sugerida: Os períodos simples são: "A primeira camada da Terra é a Crosta terrestre"; "Abaixo da crosta terrestre encontra-se a Descontinuidade de Mohorovicic ou simplesmente Moho"; "A segunda camada da Terra é o Manto; Logo abaixo do manto encontra-se outra descontinuidade, a de Wiechert-Gutenberg, também conbecida somente como descontinuidade de Gutenberg"; "A terceira e última das camadas da Terra é o Núcleo". Todos esses períodos iniciam os respectivos parágrafos. Ou seja, após informar a localização das camadas terrestres, outras informaçoes sobre essas camadas são apresentadas ao longo dos parágrafos.

Sobre a habilidade a ser desenvolvida no aluno - "Identificar, em texto ou sequência textual, orações como unidades constituídas em torno de um núcleo verbal e períodos como conjuntos de orações conectadas" -, salientamos a inconsistência na definição dos períodos como conjuntos de orações conectadas. $\mathrm{Na}$ realidade, o documento refere-se particularmente aos períodos compostos, pois as orações isoladas são reconhecidas como períodos simples.

Ao focalizar a estrutura da frase, as questões foram elaboradas para desenvolver o pensamento crítico e questionador dos alunos. A própria gramática foi utilizada como material de consulta passível de críticas, conforme a orientação para os alunos analisarem a definição de verbo apresentada por Bechara (2010), considerando os usos das referidas formas linguísticas no texto de referência, marcado predominantemente pela tipologia textual descritiva, dado o caráter didático do gênero. Em outras palavras, a atividade não se resumiu à prática de identificação de categorias gramaticais no texto.

Em síntese, destacamos que, numa abordagem reflexiva (SIGILIANO; SILVA, 2017), assim como as questões sobre as formas verbais, as referentes à composição dos períodos e orações gramaticais foram elaboradas com propósitos de possibilitar ao aluno compreender: (1) que as escolhas ou usos das formas linguísticas nos textos provocam efeitos de sentido; (2) 
que a gramatica auxilia na organização das informações nos parágrafos e, consequentemente, na integridade textual.

\section{Considerações finais}

Este artigo nos permitiu mostrar a apropriação de conhecimentos sobre alfabetização e letramento por professoras matriculadas no mestrado profissional. Os conhecimentos foram construídos para a própria disciplina Alfabetização e Letramento, ofertada no referido mestrado e lócus desta pesquisa, para as aulas de LP sob a responsabilidade das próprias professoras ou outras profissionais atuantes nas escolas de ensino básico. Assumindo a abordagem do letramento científico, o formador responsável pela disciplina no mestrado orientou as professoras a produzirem textos, sobre os quais, posteriormente, elas mesmas se debruçaram como pesquisadoras. Nessa dinâmica, distintas noções de alfabetização e letramento foram elaboradas, identificadas e adaptadas em função da instauração do alinhamento necessário entre os conhecimentos em construção no curso e os recomendados na BNCC (BRASIL, 2017), resultando, finalmente, na elaboração de uma atividade pedagógica com encaminhamento interdisciplinar.

O percurso desta pesquisa nos revelou que: (1) o desempenho insuficiente dos alunos em práticas de leitura e escrita se configura como um grande desafio enfrentado pelas professoras no local de trabalho; (2) as teorias científicas podem auxiliar as professoras a construírem olhares críticos e investigativos sobre as próprias práticas profissionais; (3) as abordagens da alfabetização e do letramento podem orientar o trabalho pedagógico nas aulas dos diferentes componentes curriculares, ao longo dos anos escolares do ensino fundamental; e (4) a formação oferecida às professoras no mestrado profissional precisa conciliar estudos teóricos, demandas da prática profissional e, inclusive, produção cooperativa de conhecimentos por professoras e formadores.

A respeito da terceira versão preliminar da BNCC (BRASIL, 2017), esta pesquisa mostrou que a aprovação definitiva do documento pode se configurar em retrocesso para as práticas de ensino do português como língua materna no território brasileiro. No eixo de conhecimentos linguísticos e gramaticais, focalizado mais diretamente neste artigo, são simplesmente listados os objetos de conhecimento e as habilidades a 
serem desenvolvidas, trazendo inúmeros conteúdos e metalinguagens da tradição gramatical. Na ausência de encaminhamentos metodológicos, os conteúdos selecionados podem acionar as práticas pedagógicas improdutivas características das aulas tradicionais de LP.

No tocante à atividade pedagógica exemplificada, acreditamos que nossa contribuição maior esteja nas estratégias ou procedimentos metodológicos utilizados na elaboração, os quais podem servir de modelo para a criação de outras atividades. Finalmente, destacamos a importância de grandes investimentos na formação continuada de professoras, a exemplo dos mestrados profissionais para educadores, pois as transformações necessárias no ensino básico dependem principalmente da educação de professoras autônomas e produtoras de conhecimento, portanto pesquisadoras.

\section{Agradecimentos}

Agradecemos as contribuições dos pareceristas anônimos deste artigo; as possíveis fragilidades restantes neste texto, porém, são da nossa completa responsabilidade. O primeiro autor deste artigo agradece ao Conselho Nacional de Desenvolvimento Científico e Tecnológico (CNPq) pela bolsa de produtividade em pesquisa (PQ-2) concedida, contribuindo portanto para produção da pesquisa aqui apresentada (Processo 305094/2016-5).

\section{Referências}

AKDUR, T. E. Scientific literacy: the development of some components of scientific literacy in basic education. Saarbrücken: Verlag Dr. Müller, 2009.

APARÍCIO, A. S. M. Modos individuais e coletivos de produzir a inovação no ensino de gramática em sala de aula. Revista Brasileira Linguística Aplicada, Belo Horizonte, v. 10, n. 4, p. 883-907, 2010. DOI: https://doi.org/10.1590/S198463982010000400004

BECHARA, E. Gramática escolar da língua portuguesa. 2. ed. Rio de Janeiro: Nova Fronteira, 2010.

BRASIL. Parâmetros curriculares nacionais: primeiro e segundo ciclos do ensino fundamental: Língua Portuguesa. Brasília: MEC/SEF, 1997. Disponível em: <https://goo.gl/jyzVw6>. Acesso em: 12 jan. 2018. 
BRASIL. Parâmetros Curriculares Nacionais: terceiro e quarto ciclos do ensino fundamental: Língua Portuguesa. Brasília: MEC/SEF, 1998. Disponível em: $<$ https://goo.gl/mSiGgK>. Acesso em: 12 jan. 2018.

BRASIL. Base Nacional Comum Curricular. educação é a base. (Versão Abril 2017) Brasília: MEC, 2017. Disponível em: <https://goo.gl/bDM4YP>. Acesso em: 12 jan. 2018.

CHASSOT, A. Alfabetização científica: questões e desafios para a educação. 6. ed. Ijuí: Unijuí, 2014.

CUNHA, R. B. Alfabetização científica ou letramento científico? Interesses envolvidos nas interpretações da noção de scientific literacy. Revista Brasileira de Educação, Rio de Janeiro, v. 22, n. 68, p. 169-186, 2017.

DEMO, P. Saberpensar é questionar. Brasília: Liber Livro, 2010.

DOLZ, J.; GAGNON, R.; DECÂNDIO, F. Produção escrita e dificuldades de aprendizagem. Tradução de Fabrício Decândio e Anna Rachel Machado. Campinas: Mercado de Letras, 2010.

FOUCAULT, M. O que é a crítica? Seguido de a cultura de si. Lisboa: Texto \& Grafia, 2017.

FRANCHI, C. Criatividade e gramática. In: POSSENTI, S. (Org.). Mas o que é mesmo gramática? São Paulo: Parábola, 2006. p. 34-101.

FREIRE, P. Alfabetização: leitura do mundo, leitura da palavra. São Paulo: Paz e Terra, 1990.

HEATH, S. B. Ways with words: language, life and work in communities and classrooms. Cambridge: Cambridge University Press, 1983.

LÜDKE, M.; ANDRÉ, M. Pesquisa em educação: abordagens qualitativas. São Paulo: EPU, 2013.

NEVES, M. H M. Gramática na escola. São Paulo: Editora Contexto, 1999.

PENA, R. F. A. Camadas da Terra. Brasil Escola, São Paulo, [20--?]. Disponível em: $<$ https://goo.gl/SgBPm8 >. Acesso em: 12 jan. 2018.

REIS, A. P. Letramento cientifico como prática inovadora numa escola pública araguainense. 2016. 230 f. Dissertação (Mestrado Profissional em Letras) - Universidade Federal do Tocantins, Araguaína, 2016.

SANTOS, W. L. P. Educação científica na perspectiva de letramento como prática social: funções, princípios e desafios. Revista Brasileira de Educaşão, Rio de Janeiro, v. 12, n. 36, p. 474-492, 2007. 
SANTOS, B. S. Para além do pensamento abissal: das linhas globais a uma ecologia de saberes. In: SANTOS, B.; MENEZES, M. P. (Org.). Epistemologia do sul. São Paulo: Cortez, 2010. p. 31-83.

SILVA, W. R. Estudo da gramática no texto: demandas para o ensino e a formação do professor de língua materna. Maringá: Eduem, 2011.

SILVA, W. R. Letramento e fracasso escolar. o ensino da língua materna. Manaus: UEA, 2012.

SILVA, W. R. Gêneros em práticas escolares de linguagens: currículo e formação do professor. Revista Brasileira de Linguística Aplicada, Belo Horizonte, v. 15, n. 4, p. 1023-1055, 2015. DOI: https://doi.org/10.1590/1984-639820156170

SILVA, W. R. Letramento científico na formação inicial do professor. Práticas de Linguagem, Juiz de Fora, v. 6, p. 8-23, 2016. Número especial.

SILVA, W. R. et al. Proposta de atividade interdisciplinar para o estudo das línguas portuguesa e inglesa: uma experiência mediada pela pesquisa no mestrado profissional para professores. A cor das letras, Feira de Santana, v. 18, p. 163-181, 2017. Número especial.

SILVA, W. R; SOUSA, W. B.; ARAÚJO, S. F. C. Construção de saberes no mestrado profissional em Letras: uma experiência compartilhada. Leia escola, Campina Grande, v. 17, n. 1, p. 32-44, 2017.

SIGILIANO, N.; SILVA, W. R. Diagnóstico de propostas de análise linguística em livros didáticos aprovados em programa oficial. In: MAGALHÃES, T.; GARCIAREIS, A.; FERREIRA, H. (Org.). Concep̧cão discursiva de linguagem: ensino e formação docente. Campinas: Pontes, 2017. p. 19-40.

SILVEIRA, R. A. Abordagem interdisciplinar de práticas pedagógicas sustentáveis de letramentos numa escola tocantinense de tempo integral.2016.216 f. Dissertação (Mestrado Profissional em Letras) - Universidade Federal do Tocantins, Araguaína, 2016.

SOARES, M. Letramento: um tema em três gêneros. 2. ed. Belo Horizonte: Autêntica, 2001.

SOARES, M. Alfabetização: a questão dos métodos. São Paulo: Contexto, 2016.

STREET, B. V. Letramentos sociais: abordagens críticas do letramento no desenvolvimento, na etnografia e na educação. Tradução de Marcos Bagno. São Paulo: Parábola, 2014.

TFOUNI, L. V. Letramento e alfabetização. 4. ed. São Paulo: Cortez, 2002. 


\section{ANEXO: Texto de referência da atividade pedagógica proposta}

\section{CAMADAS DA TERRA}

As camadas da Terra são a representação da estrutura interna do nosso planeta.

A estrutura interna da Terra, isto é, toda a composição do planeta formada pela superfície e tudo o que abaixo dela se encontra, é formada por várias formas, temperaturas, aspectos e composições químicas. Para um melhor entendimento sobre como está estruturado o planeta, elaborou-se uma classificação que deu origem ao que hoje compreendemos por camadas da Terra.

Ao todo, o planeta apresenta três principais camadas e duas descontinuidades, que são as estruturas encontradas entre uma camada e outra. Confira o esquema a seguir:

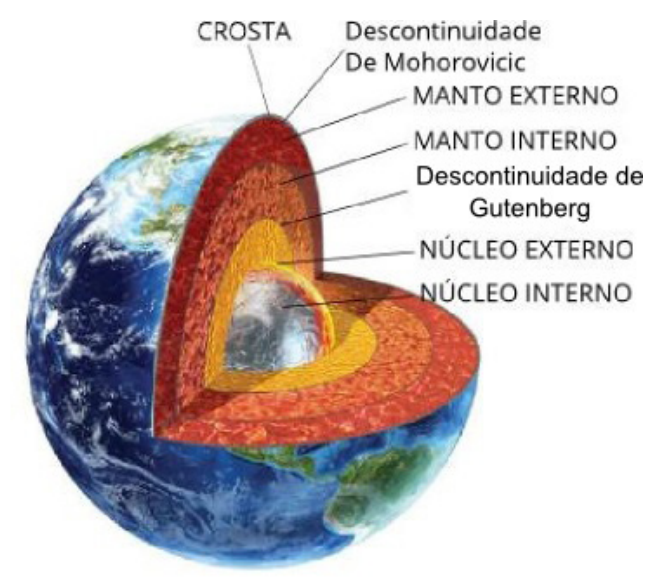

Esquema explicativo das camadas da Terra

A primeira camada da Terra é a Crosta terrestre. É a menor das estruturas do planeta, mas é a mais importante para as atividades humanas. Ela é fundamentalmente composta por rochas leves, tendo como minerais predominantes o silício, o alumínio e o magnésio. Nas zonas continentais, apresenta uma variação de 20 a $70 \mathrm{~km}$ de espessura, medidas que diminuem nas zonas oceânicas, onde a variação é de 5 a $15 \mathrm{~km}$.

Abaixo da crosta terrestre encontra-se a Descontinuidade de Mohorovicic ou simplesmente Moho. Nela, as variações sísmicas costumam ser mais rápidas e mais fluidas em relação à sua composição externa.

A segunda camada da Terra é o Manto. Este apresenta profundidades que vão dos $30 \mathrm{~km}$ abaixo da superfície até $2.900 \mathrm{~km}$, além de temperaturas internas que chegam 
a alcançar os $2.000^{\circ} \mathrm{C}$, o que propicia o derretimento das rochas, transformando-as em magma. No manto interno, o material é mais líquido, haja vista que as temperaturas são maiores; já no manto externo o material magmático é mais pastoso.

Logo abaixo do manto encontra-se outra descontinuidade, a de WiechertGutenberg, também conhecida somente como descontinuidade de Gutenberg. Ela encontra-se totalmente em estado líquido e apresenta temperaturas maiores que as do manto.

A terceira e última das camadas da Terra é o Núcleo. Não se sabe exatamente qual é a sua composição, mas há fortes indícios de que ele seja formado por uma liga de ferro e níquel, que também deve envolver outro elemento químico ainda desconhecido. O núcleo externo encontra-se no estado líquido e o núcleo interno é sólido em virtude da influência da pressão interna do planeta sobre ele.

Atualmente, sabe-se que o núcleo interno da Terra gira a uma velocidade maior do que o próprio movimento de rotação do planeta. Isso porque, como o núcleo externo é líquido, o núcleo interno fica imerso nessa verdadeira "câmara" de magma derretido, que o isola das camadas restantes. $\mathrm{O}$ fato de ele girar em grandes velocidades indica que o planeta também girava mais rápido em tempos remotos.

Por Rodolfo Alves Pena (Graduado em Geografia) Fonte: Pena, [20--?].

Data de submissão: 09/07/2017. Data de aprovação: 05/01/2018. 